\title{
Endothelin-1 production is associated with eosinophilic rather than neutrophilic airway inflammation
}

\author{
F. Finsnes, ${ }^{*+}$, O.H. Skjønsberg*, T. Lyberg ${ }^{\#}$, G. Christensen ${ }^{+}$
}

\begin{abstract}
Endothelin-1 production is associated with eosinophilic rather than neutrophilic airway inflammation. F. Finsnes, O.H. Skjonsberg, T. Lyberg, G. Christensen. (C)ERS Journals Ltd 2000.

ABSTRACT: Endothelin-1 (ET-1) is a strong bronchoconstrictor which possesses proinflammatory properties and is claimed to be an important mediator in bronchial asthma. The present study was undertaken to investigate whether ET-1 synthesis, in an inflammation dominated by neutrophilic granulocytes, is as pronounced as previously demonstrated in an airway inflammation dominated by eosinophils. Moreover, the authors compared the production of ET-1 and tumour necrosis factor (TNF)- $\alpha$ in rat lungs following intratracheal instillation of either lipopolysaccharide (LPS) (neutrophilic inflammation) or Sephadex (SDX) (eosinophilic).

The lung tissue ET-1 messenger ribonucleic acid (mRNA) expression was not increased in LPS treated animals whereas a six-fold increase was measured after 30 min in the SDX group $(p<0.05)$. TNF- $\alpha$ mRNA signals increased early following LPS instillation, peaking at $2 \mathrm{~h}$, whereas elevated TNF- $\alpha$ mRNA in the SDX model was observed at $24 \mathrm{~h}$. The ET-1 concentrations in bronchoalveolar lavage fluid (BALF) rose slightly, but significantly, $3 \mathrm{~h}$ after both LPS and SDX exposure. At $24 \mathrm{~h}$ no further rise in ET-1 levels was observed in the LPS model, while a substantial increase in the ET-1 concentration was measured in the SDX group $(p<0.05)$. The TNF- $\alpha$ concentrations in BALF rose considerably at $3 \mathrm{~h}$ in the LPS group, but was nearly abolished at $24 \mathrm{~h}$. In SDX challenged animals however, an increase in BALF-TNF- $\alpha$ did not occur until $24 \mathrm{~h}$ postchallenge.

In conclusion, intratracheal instillation of lipopolysaccharide, leading to a purely neutrophilic lung inflammation, does not induce synthesis of endothelin-1. This is in contrast to observations during an eosinophilic airway inflammation, indicating a specific role of endothelin-1 in lung inflammations dominated by eosinophils. In contrast to in vitro experiments, no evidence for induction of endothelin-1 synthesis was observed by high levels of tumour necrosis factor- $\alpha$ in vivo.

Eur Respir J 2000; 15: 743-750.
\end{abstract} *Dept of Pulmonary Medicine, ${ }^{+}$Institute
for Experimental Medical Research, ${ }^{\#}$ Re-
search Forum, University of Oslo, Ulleval
Hospital, Oslo, Norway.

Correspondence: F. Finsnes, Institute for Experimental Medical Research Ulleval Hospital, 0407 Oslo, Norway Fax: 47 51548489

Keywords: Airways

endothelin-1

inflammation

tumour necrosis factor- $\alpha$

Received: March 311999

Accepted after revision December 151999

This study was supported by grants from the Norwegian Research Council, the Anders Jahre's Fund for the Promotion of Science and GlaxoWellcome Norway.
Endothelin (ET)-1 may play a key role in the development of an eosinophilic airway inflammation [1-3], such as bronchial asthma [4-6]. ET-1 has also been claimed to be of importance in other inflammatory lung disorders $[5$, $7,8]$. Since the lungs have been shown to be a major source of ET-1 [9] in addition to having a very high receptor density for this peptide [9], it could be speculated that ET-1 would be of importance as a general pro-inflammatory mediator in this organ. In order to investigate whether ET-1 synthesis is a preponderant feature of other than eosinophilic lung inflammations, ET-1 synthesis and release in lungs from lipopolysaccharide (LPS)-challenged rats was examined. Intratracheal (IT) LPS instillation in rats induces a massive infiltration of neutrophils in lung tissue, a pattern with similarities to human adult respiratory distress syndrome (ARDS) [10]. This neutrophilic inflammation was compared to the eosinophilic inflammation induced by intratracheally instillation of the dextran Sephadex (SDX), which promotes a strong production of ET-1 $[1,2,11]$.

Studies have suggested that tumour necrosis factor (TNF)- $\alpha$ is a critical cytokine responsible for the inflam- mation observed after exposure to LPS $[12,13]$. TNF- $\alpha$ has also been implicated as a primary mediator of eosinophilic airway inflammation, since it has strong proinflammatory properties [14, 15] and causes bronchial hyperresponsiveness [15]. TNF- $\alpha$ is elevated in bronchoalveolar lavage fluid (BALF) of symptomatic compared to asymptomatic asthma patients [16], and might be one principal trigger of allergic airway inflammation [17]. Interestingly, there seems to be a link between ET-1 and TNF- $\alpha$, since in vitro studies have shown that TNF- $\alpha$ may induce ET-1 production in airway epithelial cells [18-21]. Conversely, ET-1 may also stimulate the biosynthesis of TNF- $\alpha[22,23]$. In addition, to study the generation of ET-1 in both a neutrophilic and eosinophilic airway inflammation, the synthesis and release of TNF- $\alpha$ in relation to ET-1 in these in vivo models was examined.

Rats challenged with either LPS or SDX were evaluated with ET-1 messenger ribonucleic acid (mRNA) and TNF$\alpha$ mRNA analyses in lung tissues $15 \mathrm{~min}, 30 \mathrm{~min}, 1 \mathrm{~h}, 2,3$, 12,24 and $48 \mathrm{~h}$ after provocation. In additional experiments, the concentration of the ET- 1 and TNF- $\alpha$ peptides and cell profiles in BALF, as well as histological evaluation, were 
performed $3 \mathrm{~h}$ and $24 \mathrm{~h}$ after IT provocation with LPS, SDX or saline.

\section{Methods}

\section{Experimental procedure}

Ninety-six male Wistar rats weighing 300-320 g (M\&B, Ejby, Denmark) were maintained and housed in accordance with the conditions set by the Norwegian Council for Animal Research. The investigation conformed with the National Institutes of Health guidelines (NIH publication no.85-23 revised 1985). The animals were anaesthetized with isofluran (Abbott Laboratories, Chicago, IL, USA), and a suspension $(0.3 \mathrm{~mL}$ total volume $)$ of either SDX (G200 Superfine; Pharmacia \& Upjohn, Uppsala, Sweden) 5 $\mathrm{mg} \cdot \mathrm{mL}^{-1}$ or LPS (Sigma Chemicals Co., St. Louis, MO, USA) $20 \mu \mathrm{g} \cdot \mathrm{mL}^{-1}$ was instilled intratracheally. The animals were euthanized at $15 \mathrm{~min}, 30 \mathrm{~min}, 1 \mathrm{~h}, 2,3,6,12,24$ and $48 \mathrm{~h}$ after induced inflammation $(\mathrm{n}=3$ in each group receiving either SDX or LPS, respectively). In separate experiments bronchoalveolar lavage was performed as previously described by instillation of $3+2+2 \mathrm{~mL}$ phosphate buffered saline (PBS) in the right stem bronchus, distal to the upper lobe, and the procedure was repeated on the left side in groups of six animals at $3 \mathrm{~h}$ and $24 \mathrm{~h}$ after IT provocation with either SDX, LPS or PBS (control animals), respectively.

\section{Analysis of bronchoalveolar lavage fluid and lung tissues}

The lavage fluid was handled as previously described [2]. Briefly, the BALF was collected into prechilled ethylenediamine tetraacetic acid (EDTA)-containing tubes and kept on ice until centrifuged. The cell pellet was resuspended in PBS, counted in a Bürker haemocytometer, cytospin slides were stained using Diff-Quick $\mathbb{R}$ solution (Baxter Diagnostics AG, Düdingen, Switzerland) and at least 400 nonepithelial cells were determined for differential cell counts.

The BALF supernatant was stored at $-70^{\circ} \mathrm{C}$ until analysed. ET-1 peptide content in BAL lavage was determined using an radioimmuno-linked ET-1-21 specific assay system (RPA 555; from Amersham International, Cardiff, UK), [1]. TNF- $\alpha$ was measured using a rat specific sandwich enzyme-linked immunosorbent assay (ELISA) (Factor-Test-X $\mathbb{R}$; Genzyme Corporation, Cambridge, MA, USA).

The lungs for mRNA analyses were snap-frozen in liquid nitrogen for later tissue ribonucleic acid (RNA) extraction, whereas for morphological analyses the lungs were fixed in $4 \%$ formaldehyde. Blocks of tissues were embedded in paraffin, and $5 \mu \mathrm{m}$ thick sections were prepared and stained with haematoxylin and eosin.

\section{Northern and slot blot analysis}

MRNA was extracted from homogenized lung tissue using oligo-deoxythymidine(dT)-conjugated paramagnetic beads according to the manufacturer's instructions (Dynal $\mathrm{A} / \mathrm{S}$, Oslo, Norway). The poly $\mathrm{A}^{+} \mathrm{RNA}$ was denatured in a solution containing $60 \%$ formamide, $7.2 \%$ formaldehyde, $24 \mathrm{mM}$ Hepes, $6 \mathrm{mM}$ sodium acetate and $1.2 \mathrm{mM}$ EDTA,

subsequently size-fractionated on a formaldehyde-agarose gel using $15 \mu \mathrm{g}$ poly $\mathrm{A}^{+}$RNA per lane, transferred to a Biotrans nylon membrane (ICN Biomedicals Inc., Aurora $\mathrm{OH}$, USA) by capillary blotting and hybridized with radiolabelled complementary deoxyribonucleic acid (cDNA) probes for prepro-ET-1 and glyceraldehyde-3-phosphate dehydrogenase (GAPDH). For slot blot analyses, 0.5, 1.0 and $2.0 \mu \mathrm{g}$ poly $\mathrm{A}^{+}$RNA was loaded onto the nylon membrane of a Minifold II cassette (Schleicher \& Schuell, Dassel, Germany), respectively. The nylon membranes were pre-hybridized at $42^{\circ} \mathrm{C}$ for $3 \mathrm{~h}$ in a solution containing $5 \times$ standard saline citrate (SSC), $5 \times$ Denhardt's solution, and $0.1 \%$ sodium dodecyl sulfate (SDS) and were then hybridized with ${ }^{32} \mathrm{P}$-labelled cDNA probes in the same solution at $42^{\circ} \mathrm{C}$ for $17 \mathrm{~h}$. The filters were finally washed twice in 2 $\times \mathrm{SSC}$ with $0.1 \%$ SDS at room temperature for $5 \times 5 \mathrm{~min}$ before washing twice with $0.1 \times \mathrm{SSC}$ at $60^{\circ} \mathrm{C}$ for $15 \mathrm{~min}$. and then subjected to autoradiography. Hybridization of gels was performed at $42^{\circ} \mathrm{C}$, sequentially with ET-1, TNF$\alpha$ and GAPDH cDNA probes. The rat ET- 1 cDNA probe was provided by T. Miyauchi and the TNF- $\alpha$ cDNA was a kind gift from J. Gauldie. Northern blot analysis demonstrated a single band of $\sim 2.3 \mathrm{~kb}$ for the ET- 1 mRNA probe, and $\sim 1.9 \mathrm{~kb}$ for the TNF- $\alpha$ mRNA probe (fig. 1).

a)

C $\quad 30 \mathrm{~min}$

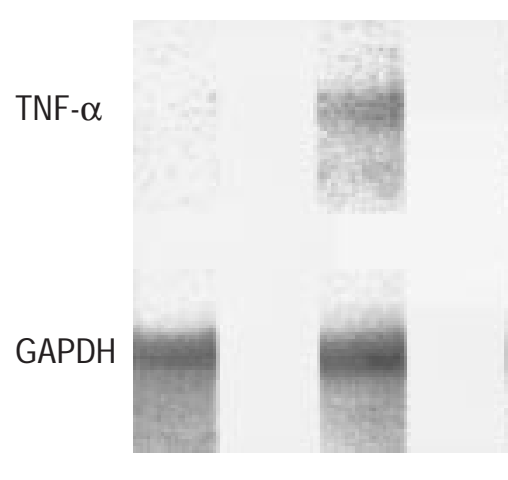

b)

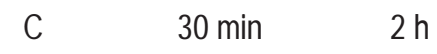

ET-1

GAPDH

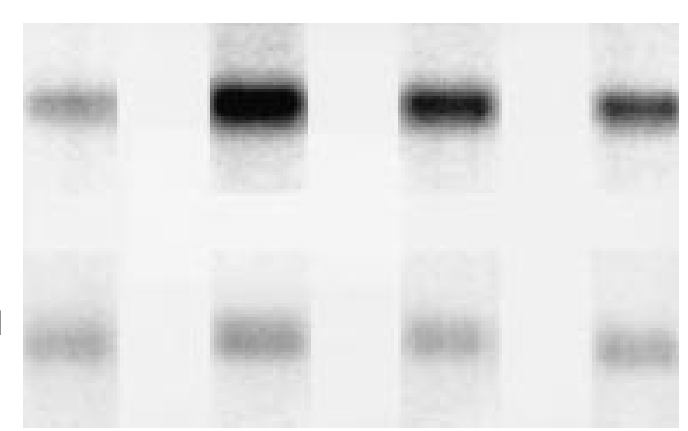

Fig. 1. - Northern blot analysis demonstrates a single band of $\sim 2.3 \mathrm{~kb}$ for the endothelin-1 probe, and $\sim 1.9 \mathrm{~kb}$ for the tumour necrosis factor (TNF)- $\alpha$ probe. a) expression of TNF- $\alpha$ (mRNA) and the corresponding glyceraldehyde-3-phosphate dehydrogenase (GAPDH) mRNA from lipopolysaccharide-provoked lung tissues. b) the ET-1 mRNA signals from animals challenged with Sephadex and the corresponding membranes rehybridized with GAPDH complimentary deoxyribonucleic acid probe. c: control. 
Autoradiography of the filters was carried out in a storage phosphorscreen and analysed by densitometric scanning analysis using the ImageQuant Version 3.3 software from Molecular Dynamics Lab., (Sunnyvale, CA, USA). To estimate the ET-1 mRNA and TNF- $\alpha$ mRNA tissue levels, the ratios to GAPDH were determined in each sample.

\section{Statistical analysis}

All values are expressed as mean \pm SEM. Statistical analyses were performed using scientific statistical software (SigmaStat version 2.0; Jandel Scientific GmbH, Ekrath, Germany). The groups were compared using the Kruskal-Wallis test followed by Dunn's or Tukey test for multiple comparisons when appropriate. Comparisons between groups were performed using the Mann-Whitney Rank Sum test. A p-value of $<0.05$ was considered statistically significant.

\section{Results}

Cell profile, endothelin and tumour necrosis factor concentrations in bronchoalveolar lavage fluid

Three hours following LPS instillation, a significant increase in total cell counts in BALF occurred, compared to rats receiving saline (fig. 2). Twenty-four hours after LPS-induced inflammation, the total cell counts were even higher than after $3 \mathrm{~h}$ being increased 20 -fold compared to control animals (fig. 2). After SDX-challenge there was no increase in total cell counts until $24 \mathrm{~h}$ later when a four-fold increase was observed.

The differential cell profile revealed a significant increase in neutrophils in both LPS and SDX-provoked animals both $3 \mathrm{~h}$ and $24 \mathrm{~h}$ after provocation, compared to control animals (fig. 3a). However, at $3 \mathrm{~h}$ the percentage of neutrophils was significantly higher in the LPS than in the SDX group, accounting for $78 \%$ and $9 \%$ of the leukocytes, respectively. Twenty-four hours after challenge

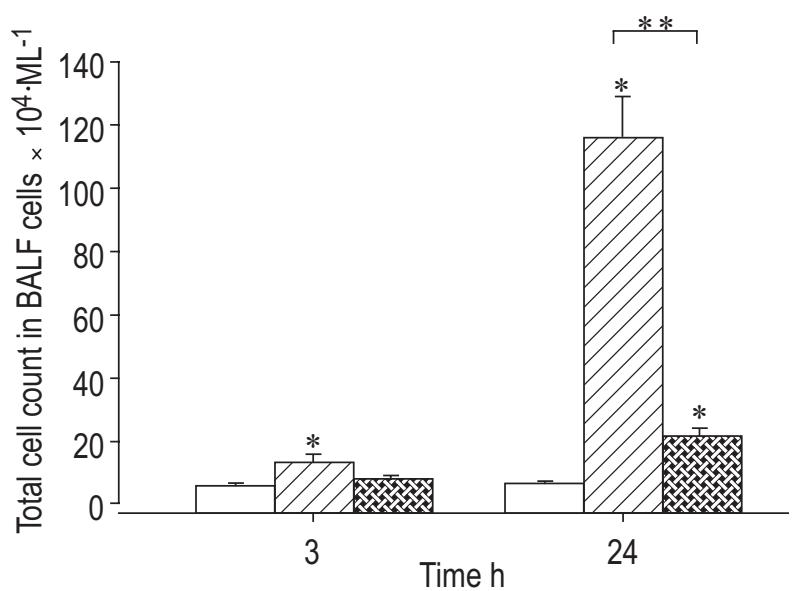

Fig. 2. - Total cell count in bronchoalveolar lavage fluid (BALF) in animals receiving saline $(\square)$, lipopolysaccharide $(\mathbb{Z})$ or Sephadex (网) intratracheally, evaluated $3 \mathrm{~h}$ and $24 \mathrm{~h}$ after instillation, respectively ( $\mathrm{n}=6$ in each group). *: significant difference compared to control animals at the time points studied; **: significant difference between LPS and SDX $(\mathrm{p}<0.05)$. Values are given as mean \pm SEM. the relative neutrophil count did not increase further in the SDX group. In the LPS group the neutrophilic response was higher, now accounting for $90 \%$ of the cells (fig. $3 \mathrm{a}$ ). No significant increase in the ratio of eosinophils in either group was observed $3 \mathrm{~h}$ after provocation (fig. 3b). At 24 $\mathrm{h}$, however, a profound increase in eosinophils $(34 \%)$ occurred in the SDX-treated animals, while no such increase could be observed in the LPS-treated rats (fig. 3b).

Histological examination of lung tissues confirmed a diffuse neutrophilic inflammation $3 \mathrm{~h}$ after LPS instillation with increased intracapillary and alveolar cellularity, while at this stage no obvious signs of inflammation were observed in the SDX group (fig. 4). After $24 \mathrm{~h}$, a homogenous, fulminate neutrophilic lung inflammation with oedema was seen in LPS treated animals as compared to the SDX challenged animals, where a more heterogenous, patchy, eosinophilic inflammation was seen peribronchially and surrounding the SDX particles (fig. 4).

The ET-1 concentrations in BALF rose significantly $3 \mathrm{~h}$ after both LPS and SDX exposure compared to saline (fig. 5a). The increase in ET-1 concentration was slightly higher in the LPS treated animals at this point of time. The observed early minor rise in BALF ET-1 remained for 24 $\mathrm{h}$ in the LPS provoked animals, whereas a pronounced 25-fold increase was measured in the SDX group (fig. 5a).

A marked increase in TNF- $\alpha$ concentration was measured in the $3 \mathrm{~h}$ LPS group and was significantly higher than in the SDX treated animals (fig. 5b). At $24 \mathrm{~h}$ the TNF- $\alpha$ levels were drastically reduced in the LPS treated animals, while a pronounced increase in the TNF- $\alpha$ concentration was observed in the SDX group, now being significantly higher than in the LPS challenged rats (fig. 5b).

\section{Messenger ribonucleic acid analysis of lung tissues}

In the LPS provoked animals, the ET-1 mRNA expression tended to be higher than in control animals at $1 \mathrm{~h}$ (NS), but for the other time points studied no increase was observed (figs. 1 and 6). Conversely, a marked elevation in ET-1 mRNA was measured $15 \mathrm{~min}$ after SDX challenge (fig. 6). In this group the maximal increase in ET-1 mRNA expression was observed at $30 \mathrm{~min}$ (six-fold increase), and following this the concentration gradually decreased (fig. 6).

Elevated TNF- $\alpha$ mRNA levels were observed $15 \mathrm{~min}$ after IT LPS provocation and the levels increased further, peaking $2 \mathrm{~h}$ after challenge (fig. 6). The TNF- $\alpha$ mRNA levels returned to baseline values after 6-12 h. In SDX provoked animals the TNF- $\alpha$ mRNA expression did not increase significantly until $48 \mathrm{~h}$ after challenge (fig. 6).

\section{Discussion}

In this study, evidence for ET-1 as a mediator mainly associated with an eosinophilic rather than a neutrophilic airway inflammation is provided. Interestingly, in contrast to in vitro experiments, no evidence for induction of ET-1 synthesis by high levels of TNF- $\alpha$ in vivo was found. The data were achieved by comparison of the inflammatory response, ET-1 and TNF- $\alpha$ production in the lungs, employing well characterized models of neutrophilic and eosinophilic lung inflammation. 

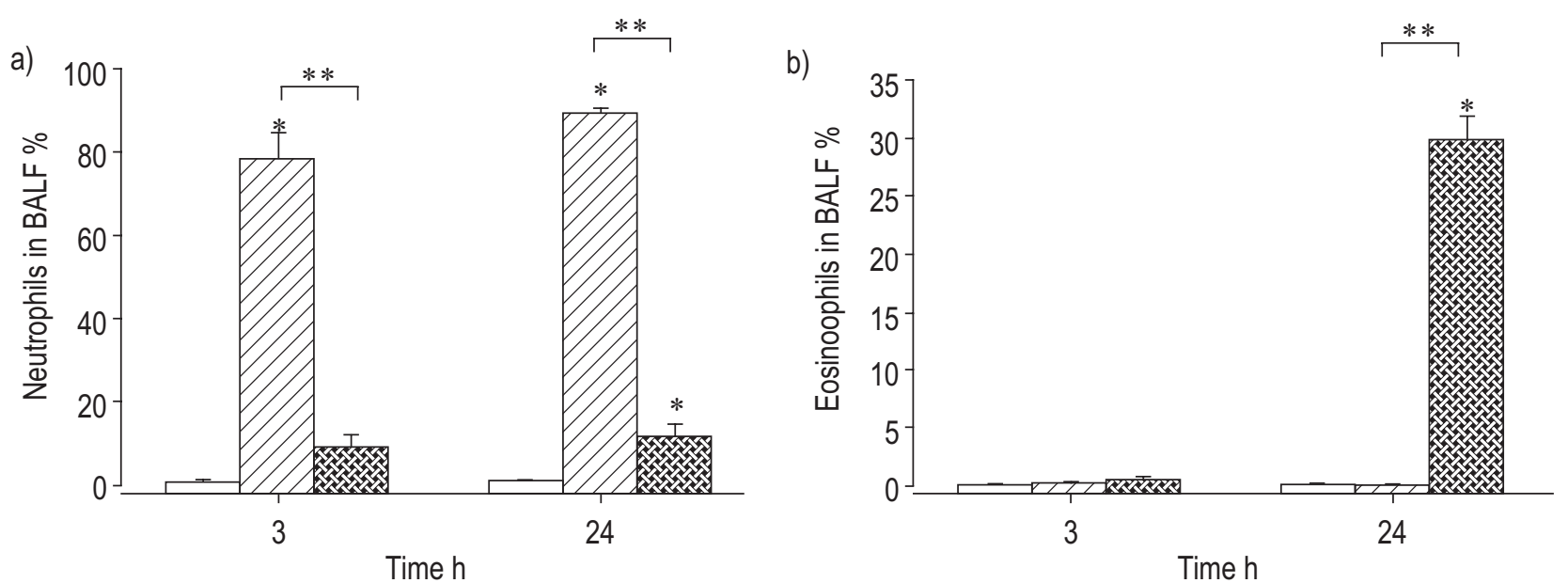

Fig. 3. - The relative proportion of bronchoalveolar lavage fluid (BALF) neutrophils (a) and eosinophils (b) in animals receiving saline ( $\square$ ),

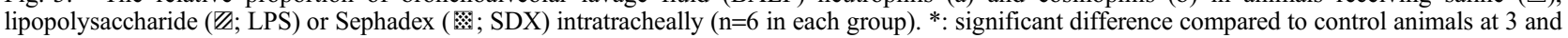
$24 \mathrm{~h}$; **: significant differences between LPS and SDX $(\mathrm{p}<0.05)$. Values are given as mean \pm SEM.

The typical feature of LPS induced lung injury is an acute inflammatory response mainly consisting of neutrophilic granulocytes. This model has been widely applied to the study of the pathophysiology of human ARDS. In addition to a large number of neutrophils that are recruited to the lung parenchyma and into the bronchoalveolar space, pulmonary oedema develops [24]. In the current study a very early and fulminate neutrophilic cellular response in BALF and in the lung tissue was observed after IT LPS instillation. Interestingly, only a modest increase in ET-1 production was found during this inflammation. This is surprising, since ET-1 has been associated with ARDS $[8,25]$ and the degree of ET-1 elevation in critically ill patients has been shown to correlate with outcome [26]. A modest, but significant, rise in BALF ET-1 was observed $3 \mathrm{~h}$ following LPS provocation, the elevation being maintained after $24 \mathrm{~h}$. However, this rise appeared in the absence of a significant increase in ET-1 mRNA production. This could possibly be due to the release of preformed ET-1 from macrophages and epithelial cells or be caused by changes in bronchial epithelial permeability. The neutrophilic inflammation could also contribute. Although neutrophils do not appear to release ET-1 per se, they can convert the precursor, big ET-1 to ET-1 by enzymatic degradation $[27,28]$.

Only one study has investigated the in vivo lung tissue expression of ET-1 after LPS injection [29]. In that study, KADDOURA et al. [29] demonstrated a fairly slow and minor increase in the ET-1 mRNA expression, the levels being less than two-fold increased after $6 \mathrm{~h}$. However, the study was conducted in order to examine the tissue expression of ET-1 in several different organs and did not confirm the extent of any pulmonary inflammation. The current authors have previously shown that the bronchial epithelial cells are an abundant source of ET-1 production after direct challenge with SDX $[1,2]$. Therefore, in the present study it seemed more appropriate to assess the ET-1 response following IT instillation of LPS than intraperitoneal LPS injection, as employed by KADDOURA et al. [29] Although the present study shows no significant increase in ET-1 mRNA and only a modest increase in peptide concentration after LPS instillation, a role for ET1 in this inflammatory process cannot be ruled out.

In SDX-treated rats, both the ET-1 mRNA increase and subsequent ET-1 peptide release into BALF are substantially higher than in LPS treated animals. The SDX model is primarily one of eosinophilic inflammation, although an early transient increase of neutrophils is observed [2]. Thus, this model shows similarities to human asthma which is likewise characterized by an eosinophilic inflammatory response, preceded by neutrophilia in asthmatic reactions [30]. The considerably higher ET-1 production in the SDX model can not be attributed to the degree of inflammation, since the extent of inflammation induced by LPS, as measured by the recruitment of inflammatory cells into BALF and tissue, is more severe. These data showing high ET-1 levels in eosinophilic airway inflammation, suggest that ET-1 production is a preponderant feature of eosinophilic rather than neutrophilic inflammation. A close relationship between the release of ET-1 in BALF and the number of eosinophils in BALF following SDX challenge has been shown [1], but the increased ET1 levels are hardly a result of eosinophilia. On the contrary, it is tempting to speculate that ET-1 is causing the eosinophilic response in this model, acting directly as a chemoattractant. This is supported by the observation of a very rapid synthesis of ET-1 mRNA in bronchial epithelial cells and macrophages following SDX-provocation, prior to the influx of inflammatory cells [2]. The current demonstration of an important role for ET-1 in eosinophilic airway inflammation is underscored by the observation of a pronounced anti-inflammatory effect of treatment with an ET receptor antagonist in IT SDXinduced inflammation [1]. This effect has later been confirmed in another study [3] that demonstrated inhibition of the infiltration of inflammatory cells into the lungs after antigen challenge in ovalbumin-sensitized mice by blockage of ET receptors.

TNF- $\alpha$ is considered to play a key role in several kinds of inflammatory conditions, including asthmatic airway inflammation [16] and human lung allergic reactions [14]. Assessment of any interaction between ET-1 and TNF- $\alpha$ 
a)

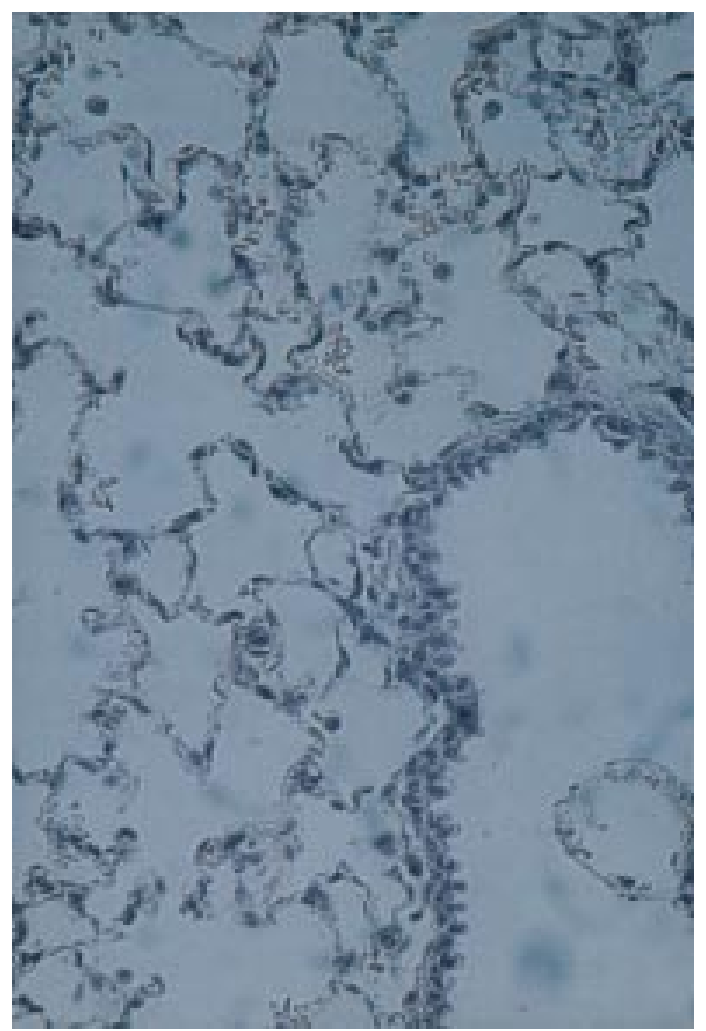

c)

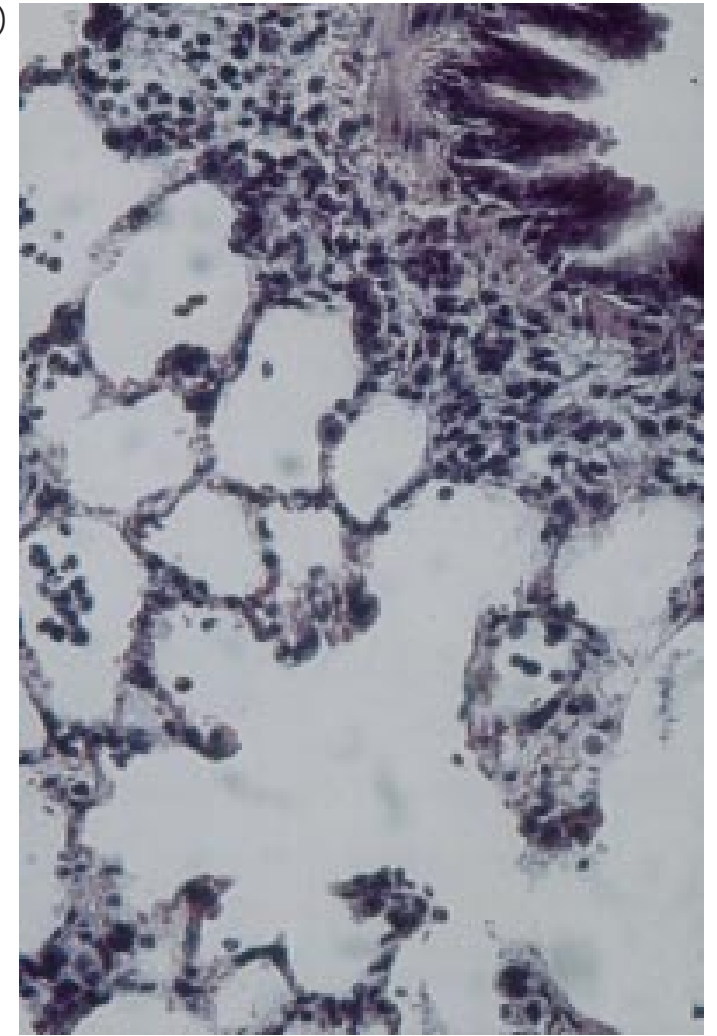

b)

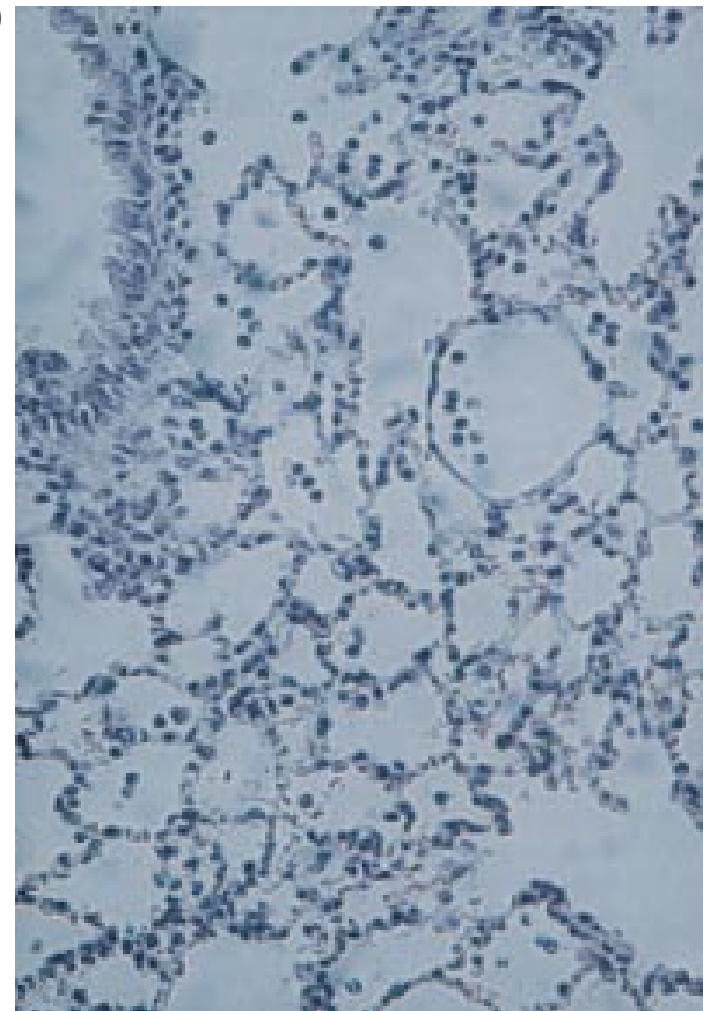

d)

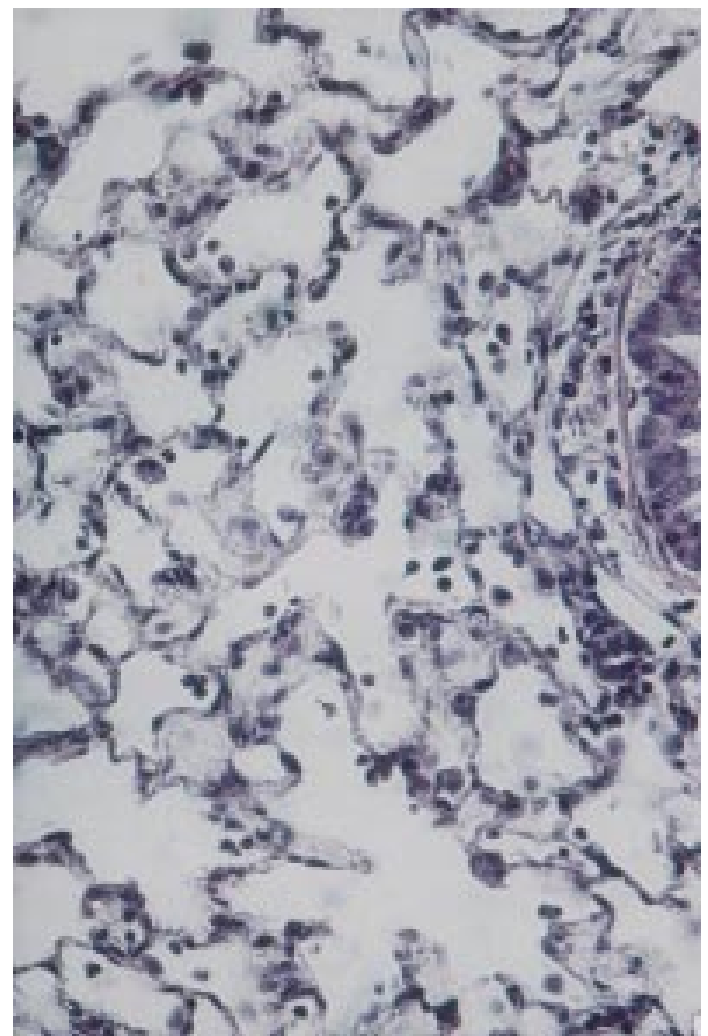

Fig. 4. - Lung tissue harvested at $3 \mathrm{~h}$ after Sephadex (SDX) challenge (a) and lipopolysaccharide (LPS) challenge (b). Note the increased intracapillary and alveolar cellularity in (b) compared to unaffected tissue in (a). Twenty-four h after SDX instillation (c) the inflammation is more localized, whereas in LPS treated animals the inflammation is more extensive with increased oedema as shown in panel (d) (peribronchial area). Haematoxylin and eosin stained, original magnification $\times 100$. 

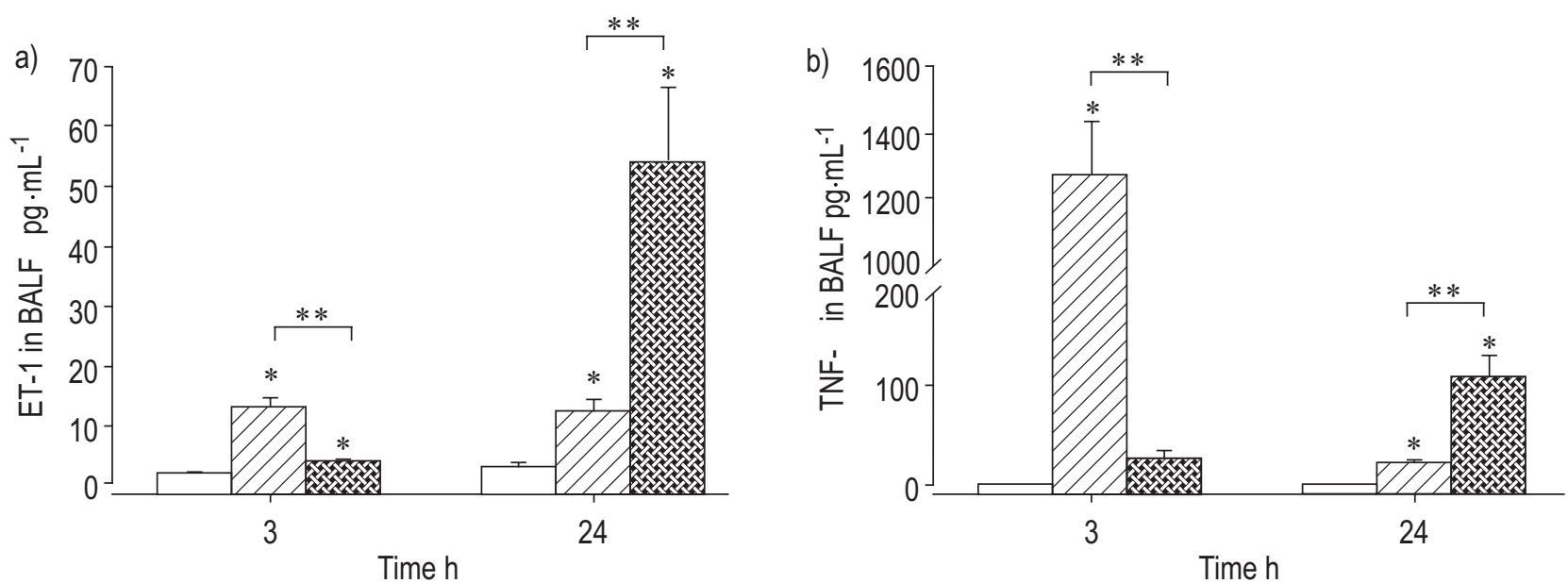

Fig. 5. - Endothelin (ET)-1 and tumour necrosis factor (TNF)- $\alpha$ concentrations in bronchoalveolar lavage fluid (BALF) in control animals ( $\square$ ) lipopolysaccharide (LPS) provoked $(\mathbb{Z})$ and sephadex (SDX; $)$ animals ( $\mathrm{n}=6$ in each group), $3 \mathrm{~h}$ and $24 \mathrm{~h}$ after challenge. $*$ : significant difference compared to control animals at $3 \mathrm{~h}$ and $24 \mathrm{~h}$; **: significant differences between LPS and $\mathrm{SDX}(\mathrm{p}<0.05)$. Values are given as mean \pm SEM.

would therefore be of interest. The lung tissue TNF- $\alpha$ mRNA expression in LPS-induced inflammation was increased from $15 \mathrm{~min}$ to $6 \mathrm{~h}$ after challenge. Compared to the $>1,000$-fold increase in TNF- $\alpha$ peptide concentration in BALF at this early stage it seems likely that the main source of TNF- $\alpha$ peptide is prestored proTNF in cytoplasm. The efficiency of TNF- $\alpha$ generation from proTNF has indeed been shown to be increased in macrophages activated by LPS exposure [13]. The main source of TNF- $\alpha$ generation is likely to be the macrophages $[13,31]$, although neutrophils are also shown to produce TNF- $\alpha$ in LPS-challenged rats [10]. Interestingly, the abundant TNF- $\alpha$ level in BALF was transient and almost abolished $24 \mathrm{~h}$ after provocation. A similar sequential pattern of TNF- $\alpha$ response and recruitment of neutrophils into BALF has been seen in a mouse LPS model [32]. In contrast, in the SDX model the TNF- $\alpha$ peptide was still increasing at $24 \mathrm{~h}$, being five-fold higher than in the LPS challenged animals. The TNF- $\alpha$ increase in BALF in this model appears secondary to the ET-1 production. The current data may suggest, firstly, that TNF- $\alpha$ does not trigger the ET-1 production in the LPS model, and secondly, that ET-1 could stimulate the TNF$\alpha$ synthesis in the SDX model.

In vitro studies support the hypothesis that ET-1 stimulates TNF- $\alpha$ release [23, 33]. In vivo, systemic administration of ET-1 to anaesthetized rats resulted in a rapid (within minutes) transient increase of the TNF- $\alpha$ concentration in plasma [23]. Both ET-1 and TNF- $\alpha$ are probably important mediators in bronchial asthma. In humans, ET-1 expression in airway epithelium is increased in asthmatic patients [4]. Moreover, inhalation of ET-1 in asthmatic subjects results in a rapid-onset, dosedependent bronchoconstriction [34]. Inhalation of TNF- $\alpha$ does not cause bronchoconstriction, but increases bronchial hyperresponsiveness and subsequently leads to an infiltration of neutrophils, as measured in induced sputum in humans [15]. One possibility, which requires further investigation, is that ET-1, in addition to bronchoconstriction, in fact induces production of the potent chemoattractant TNF- $\alpha$ in patients with bronchial asthma.
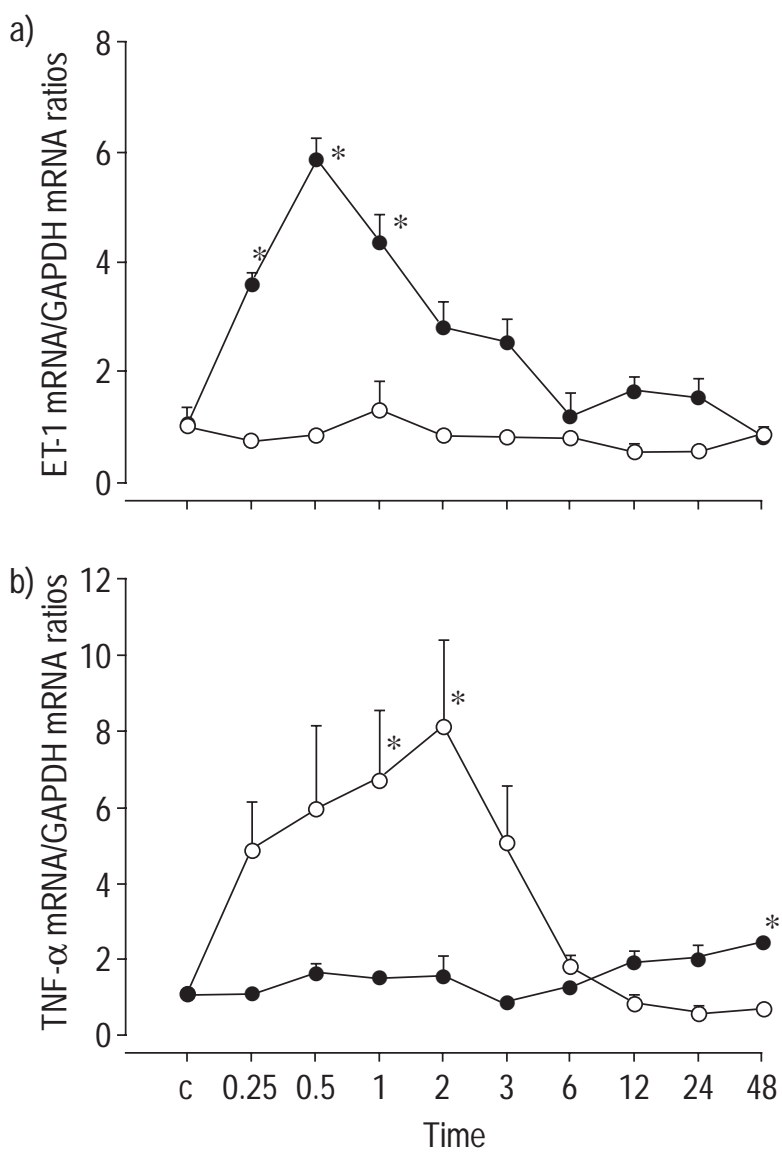

Fig. 6. - a) Lung tissue endothelin $(E T)=1$ messenger ribonucleic acid (mRNA) levels $15 \mathrm{~min}, 30 \mathrm{~min}, 1 \mathrm{~h}, 2,3,6,12,24$ and $48 \mathrm{~h}$ following intratracheal lipopolysaccharide (LPS) or Sephadex (SDX) provocation. b) Results of the tumour necrosis factor (TNF)- $\alpha$ mRNA levels after provocation at identical time points $(\mathrm{n}=3$ in each group). All measurements are adjusted for the house-keeping gene, glyceraldehyde-phosphate dehydrogenase (GAPDH). * significant difference compared to control animals $(\mathrm{p}<0.05)$. $\bigcirc$ : LPS; $\bigcirc$ : SDX. c: control. Values are given as mean \pm SEM. 
In conclusion, intratracheal instillation of lipopolysaccharide, leading to a purely neutrophilic lung inflammation, does not induce synthesis of endothelin-1. This is in contrast to observations during an eosinophilic lung inflammation, in which a pronounced synthesis of endothelin-1 is seen. The fact that lipopolysaccharide provocation induced an abundant, transient, increase in tumour necrosis factor- $\alpha$ synthesis and release without an increase in endothelin-1 synthesis indicates that tumour necrosis factor- $\alpha$ does not induce endothelin- 1 synthesis in the lungs. Taken together, endothelin- 1 does not seem to be a common denominator of all kinds of lung inflammation, the current findings rather suggest a specific role of endothelin-1 in lung inflammation dominated by eosinophils.

Acknowledgements. The authors thank U.L. Henriksen, T. Sandsbraten, A. Ødegaard, H. Kähler, T. Noren, and S. Flagestad for excellent technical assistance.

\section{References}

1. Finsnes F, Skjønsberg OH, Tønnessen T, Naess O, Lyberg T, Christensen G. Endothelin production and effects of endothelin antagonism during experimental airway inflammation. Am J Respir Crit Care Med 1997; 155: 14041412.

2. Finsnes F, Christensen G, Lyberg T, Sejersted OM, Skjønsberg $\mathrm{OH}$. Increased synthesis and release of endothelin-1 during the initial phase of airway inflammation. Am J Respir Crit Care Med 1998; 158: 1600-1606.

3. Fujitani Y, Trifilieff A, Tsuyuki S, Coyle AJ, Bertrand C. Endothelin receptor antagonists inhibit antigen-induced lung inflammation in mice. Am J Respir Crit Care Med 1997; 155: 1890-1894.

4. Springall DR, Howarth PH, Counihan H, Djukanovic R, Holgate ST, Polak JM. Endothelin immunoreactivity of airway epithelium in asthmatic patients. Lancet 1991; 337: 697-701.

5. Sofia M, Mormile M, Faraone S, et al. Increased endothelin-like immunoreactive material on bronchoalveolar lavage fluid from patients with bronchial asthma and patients with interstitial lung disease. Respiration 1993; 60: 89-99.

6. Redington AK, Springall DR, Ghatei MA, et al. Endothelin in bronchoalveolar lavage fluid and its relation to airflow obstruction in asthma. Am J Respir Crit Care Med 1995; 151: 1034-1039.

7. Giaid A, Michel RP, Stewart DJ, Sheppard M, Corrin B, Hamid Q. Expression of endothelin-1 in lungs of patients with cryptogenic fibrosing alveolitis. Lancet 1993; 341: $1550-1554$.

8. Langleben D, DeMarchie M, Laporta D, Spanier AH, Schlesinger RD, Stewart DJ. Endothelin-1 in acute lung injury and the adult respiratory distress syndrome. $\mathrm{Am}$ Rev Respir Dis 1993; 148: 1646-1650.

9. Hemsen A, Franco-Cereceda A, Matran R, Rudehill A, Lundberg JM. Occurrence, specific binding sites and functional effects of endothelin in human cardiopulmonary tissue. Eur J Pharmacol 1990; 191: 319-328.

10. Xing Z, Kirpalani H, Torry D, Jordana M, Gauldie J. Polymorphonuclear leukocytes as a significant source of tumor necrosis factor-alpha in endotoxin-challenged lung tissue. Am J Pathol 1993; 143: 1009-1015.

11. Andersson SE, Zackrisson C, Hemsen A, Lundberg JM. Regulation of lung endothelin content by the glucocorticosteroid budesonide. Biochem Biophys Res Commun 1992; 188: 1116-1121.

12. Beutler B, Milsark IW, Cerami AC. Passive immunization against cachectin/tumor necrosis factor protects mice from lethal effect of endotoxin. Science 1985; 229: 869_ 871.

13. Minei JP, Williams JG, Hill SJ, McIntyre K, Bankey PK. Augmented tumor necrosis factor response to lipopolysaccharide after thermal injury is regulated post-transcriptionally. Arch Surg 1994; 129: 1198-1203.

14. Casale TB, Costa JJ, Galli SJ. TNF alpha is important in human lung allergic reactions. Am J Respir Cell Mol Biol 1996; 15: 35-44.

15. Thomas PS, Yates DH, Barnes PJ. Tumor necrosis factoralpha increases airway responsiveness and sputum neutrophilia in normal human subjects. Am J Respir Crit Care Med 1995; 152: 76-80.

16. Broide DH, Lotz M, Cuomo AJ, Coburn DA, Federman EC, Wasserman SI. Cytokines in symptomatic asthma airways. J Allergy Clin Immunol 1992; 89: 958-967.

17. Renzetti LM, Paciorek PM, Tannu SA, et al Pharmacological evidence for tumor necrosis factor as a mediator of allergic inflammation in the airways. J Pharmacol Exp Ther 1996; 278: 847-853.

18. Endo $\mathrm{T}$, Uchida $\mathrm{Y}$, Matsumoto $\mathrm{H}$, et al. Regulation of endothelin-1 synthesis in cultured guinea pig airway epithelial cells by various cytokines. Biochem Biophys Res Commun 1992; 186: 1594-1599.

19. Nakano J, Takizawa H, Ohtoshi T, et al. Endotoxin and pro-inflammatory cytokines stimulate endothelin-1 expression and release by airway epithelial cells. Clin Exp Allergy 1994; 24: 330-336.

20. Saleh D, Furukawa K, Tsao MS, et al. Elevated expression of endothelin-1 and endothelin-converting enzyme-1 in idiopathic pulmonary fibrosis: possible involvement of proinflammatory cytokines. Am J Respir Cell Mol Biol 1997; 16: 187-193.

21. Aubert JD, Juillerat-Jeanneret L, Leuenberger P. Expression of endothelin-1 in human bronchoepithelial and monocytic cell lines: influence of tumor necrosis factoralpha and dexamethasone. Biochem Pharmacol 1997; 53: 547-552.

22. Helset E, Sildnes T, Seljelid R, Konopski ZS. Endothelin1 stimulates human monocytes in vitro to release TNF- $\alpha$, IL-1 $\beta$ and IL-6. Mediators Inflamm 1993; 2: 417-422.

23. Ruetten H, Thiemermann C. Endothelin-1 stimulates the biosynthesis of tumour necrosis factor in macrophages: ET-receptors, signal transduction and inhibition by dexamethasone. J Physiol Pharmacol 1997; 48: 675-688.

24. Yi ES, Remick DG, Lim Y, et al. The intratracheal administration of endotoxin: X. Dexamethasone downregulates neutrophil emigration and cytokine expression in vivo. Inflammation 1996; 20: 165-175.

25. Druml W, Steltzer H, Waldhausl W, et al. Endothelin-1 in adult respiratory distress syndrome. Am Rev Respir Dis 1993; 148: 1169-1173.

26. Pittet JF, Morel DR, Hemsen A, et al. Elevated plasma endothelin-1 concentrations are associated with the severity of illness in patients with sepsis. Ann Surg 1991; 213: 261-264.

27. Sessa WC, Kaw S, Hecker M, Vane JR. The biosynthesis of endothelin-1 by human polymorphonuclear leukocytes. Biochem Biophys Res Commun 1991; 174: 613-618. 
28. Tønnessen T, Ilebekk A, Naess PA, Christensen G. Inhibition of granulocyte-derived proteases reduces the increase in plasma endothelin associated with myocardial ischemia in the pig. Basic Res Cardiol 1996; 91: 289295.

29. Kaddoura S, Curzen NP, Evans TW, Firth JD, PooleWilson PA. Tissue expression of endothelin-1 mRNA in endotoxaemia. Biochem Biophys Res Commun 1996; 218 : 641-647.

30. Fabbri LM, Boschetto P, Zocca E, et al. Bronchoalveolar neutrophilia during late asthmatic reactions induced by toluene diisocyanate. Am Rev Respir Dis 1987; 136: 3642.

31. Bazzoni F, Beutler B. Seminars in medicine of the Beth
Israel Hospital, Boston: The tumor necrosis factor ligand and receptor families. $N$ Engl J Med 1996; 334: 17171725.

32. Goncalves dMV, Boris VB, Lefort J, Meager A, Chignard M. Effect of cyclooxygenase inhibitors and modulators of cyclic AMP formation on lipopolysaccharide-induced neutrophil infiltration in mouse lung. Br J Pharmacol 1996; 117: 1792-1796.

33. $\mathrm{Xu} \mathrm{J}$, Zhong NS. The interaction of tumour necrosis factor alpha and endothelin-1 in pathogenetic models of asthma. Clin Exp Allergy 1997; 27: 568-573.

34. Chalmers GW, Little SA, Patel KR, Thomson NC. Endothelin-1-induced bronchoconstriction in asthma. $\mathrm{Am}$ J Respir Crit Care Med 1997; 156: 382-388. 